\title{
TEACHING AND LEARNING ENGLISH \\ AS THE GLOBAL LANGUAGE IN THE EDUCATION SYSTEMS OF THE GLOBALIZED WORLD
}

\author{
V.M. Smokotin, G.I. Petrova, S.K. Gural
}

\begin{abstract}
The article considers the problems caused by the educational paradigm shift as a result of the English language acquiring the status of the global language in the process of globalization. The authors argue that the transformation of English into the language of worldwide communication calls forth a revision of the traditional approach to teaching foreign languages. English as the global lingua franca could no longer be treated as a foreign language. This demands a reorganization of language education based on a transition to multilingual teaching and learning in which English language teaching is envisioned not as traditional teaching of one of the national variants of English, which leads to acquiring the corresponding dominant cultures, but as teaching English as the language of world communication used for overcoming interlingual and intercultural barriers in the globalizing world.

Keywords: English as the global language; educational paradigm shift; teaching and learning English; globalization.
\end{abstract}

\section{Introduction}

As the result of information revolution and globalization of all aspects of human activities, a need for a language for overcoming interlingual and intercultural barriers led to the fundamental changes in the world's system of languages, i.e., the transformation of the English language into the language of global communication, which is an unprecedented phenomenon in history. In the historical epochs preceding the emergence of the capitalist mode of production and the industrial revolution, which led to the internationalization of trade flows and comparative growth of interlingual and intercultural contacts, international contacts in the times of peace were limited to diplomatic relations, a relatively limited trade exchange and cultural as well as scholarly connections of the enlightened elite. The exclusive elitism of those relations, particularly diplomatic ones, shifted linguistic problems of international communications to the background since the subjects of those relations were representatives of the privileged circles, whose education included the study of the most important languages [23]. By the end of the $20^{\text {th }}$ century, however, the increasing global interaction of people by means of international flows of money, ideas and cultural products, made the terms "global village" and "global language" quite fitting in describing the globalized world in which national borders were no longer barriers for creating one area of worldwide cooperation in all spheres of life. As English has assumed the role 
of the global language in the globalized world, the educational systems of the world face new challenges in providing English language skills training to the new generation of the knowledge society when English language skills have become one of the main components of the notion of literacy. However, the changes in the world's language system put in question the continuing educational practices of teaching and learning English as a foreign language on the basis of one of the main English language varieties.

In view of the educational paradigm shift, this paper aims at searching for the ways of meeting the language training challenges of the globalized world, which include not only raising English language proficiency levels in order to empower people in entering the world's economic, political and cultural areas, but ensuring that the use of English as the global language poses no threat to the linguistic and cultural diversity of the world.

\section{Research and results}

The unprecedented phenomenon in the world's system of languages, namely, the transformation of one of the international languages - English into the language of global communication, changes the generally accepted notions about foreign languages and literacy. One of the first researchers who noted the change of the educational paradigm in English language teaching was the Brazilian web-master Ricardo Schutz, who designed the educational site "English Made in Brazil" and headed a group of authors contributing language materials and research to this site. In his article "The International Language", that was first placed on the website December $20^{\text {th }}$, 2002, Schutz drew the site visitors' attention to the social changes in the course of history as the result of which illiteracy, which was common in Middle Ages, when there existed even professional scribes for writing letters, gave way to universal literacy of the population in a few centuries. Thus, the literacy level in Europe in 1700 made up from 30 to 40 percent. By the middle of the $19^{\text {th }}$ century, the literacy level reached 55 percent, and it was no longer considered as the chief qualification in human society. At present, illiteracy in the developed countries of the world has been practically eliminated. If the traditional education includes into the notion of literacy skills of reading, writing and arithmetic, then, according to Schutz's opinion, soon it will be necessary to include into the notion of elementary literacy the skill of speaking English as one's second language. Schutz holds that the English language can no longer be regarded as a foreign language since it has become the means of worldwide communication and is a required part of the system of education. "Having chosen English as the global language, Schutz claims, history has sentenced monolingualism in the not-too-distant future to illiteracy" [1]. 
The implicit recognition of the new educational paradigm according to which the English language is no longer considered as a "foreign", but as a necessary condition of "ensuring the participation of all Europeans in the new society built on knowledge", can also be found in the documents of the European Commission - "Education \& Training: Work program adopted by the European Commission in 2001" and "A New Framework Strategy for Multilingualism" (2005), which put before the European educational systems a task of achieving by the Europeans of "practical skills in, at least, two languages apart from one's native language" $[2,3]$. The authors of "A New Framework Strategy for Multilingualism" point out that a multilingual society cannot be built if the tendency of foreign language teaching being limited to the teaching of the English language is continued [3].

The tendency of changing the attitudes of linguists and political elite to the status of the English language and their recognition of the educational paradigm shift can be observed in the English language development research carried out by David Graddol on behalf of the British Council and published in 1997 and 2006. In the first research titled "The Future of English" [4], Graddol, in his own words, "analyzes the complex combination of material and cultural tendencies which will form the global destiny of the English language", and comes to the conclusion that "the future is more complex and less predictable than it was thought to be" [4: 1]. The author of the research refers to the opinion of the academic community about the advent in the $21^{\text {st }}$ century of the new "world order", in which the Internet and information technologies may lead to the changes in the traditional ways of communication. Graddol considers that in the new "world era which the humanity has entered, the language and communication will play a more central role than before in the economic, political and cultural life just at the historic moment when the global language emerges" [4: 3]. The research emphasizes the role of the English language as an important element of the global scientific, technological, economic and cultural development, but it gives a very cautious evaluation of the tendency of the English language domination in the world arena in the future: "We cannot just extrapolate on the basis of the last decades and assume that this tendency will continue without change" [4: 4]. During the following decade the English language globalization tempos continued to grow rather than slowing down. The global status of the English language can be seen when we look at the data about its use in the tourism industry. In 2004, in 74 percent of cases the English language was used in the international tourism as a means of interlingual communication among non-native speakers of English. The use of English in international tourism among the English language native speakers made up only four percent, and in twenty two percent of cases the English language was used in contacts between native and non-native speakers of the English language [5:29]. 
The following research by David Graddol published by the British Council in 2006 presents the development of the English language during the next decade as a period of its unconditional triumph as the global language in practically all spheres of human activities. According to the forecast in this research, by the end of this period three billion people will speak English, which exceeds the population of countries where English is a state language almost five times [5]. The very title of the research testifies to the change of the British Council's attitude to the development of the English language: unlike the uncertainty, characteristic of the research published in 1997, the title of this research directly emphasizes the new status of the English language and departure from regarding English as a foreign language: "Why Global English May Mean the End of English as a Foreign Language" [5].

The transformation of the English language into the global language of universal communication, and a general transition to teaching and learning English not as a foreign language (EFL), but as a second language (ESL), requires a refusal from the traditional model of the spread of the English language and its use around the world in the form of three concentric circles, which was first proposed by the American linguist of Indian descent, Braj Kachru in his ground-breaking article "Standards codification and sociolinguistic realism: The English language in the outer circle" (1985) [6]. According to Kachru's model, three concentric circles, the internal, external and expending ones, represent "types of spreading, models of acquisition and functional spheres (domains), in which the English language is used as a means of intercultural and interlingual communication" [6: 11-36]. In the internal circle, including the main English speaking countries (Great Britain, the USA, Canada, Australia, New Zealand and so on), the English language is native for the majority of the population (L1). In the external circle, including the countries in which the English language is not native for the majority of the population, but, in view of the special importance of the language in state governance, education and national economy, it has the status of the second language (L2) and is taught as ESL (English as the second language). The external circle includes India, Pakistan, the Philippines, Nigeria and other countries, where the English language has the status of the state language. The expanding circle includes all the countries in which English is not native or a second language for the majority of the population, where it is not used in government and education, and is taught in the school educational systems as a foreign language (EFL).

The changes that took place in the world by the end of the $20^{\text {th }}$ century had brought David Graddol to conclusion, presented in the English language development research published in 1997, that Kachru's concentric circles model "will no longer be useful for describing the use of the English language in the $21^{\text {st }}$ century" [4: 10]. Graddol's criticism of Kacru's model was based on "the shift of the center of gravity" from the native speakers of Eng- 
lish to the speakers of English as the second language. In Graddol's opinion, with the growth of the number of speakers of English as the second language, the future of the English language will be determined to a considerable degree by the non-native speakers, rather than by the native speakers of English. Correspondingly, instead of the concentric circles Graddol proposed three, partially overlapping each other, circles. In this research, Graddol still considers acceptable, in relation to the English language, the use of the terminology according to which all English language speakers are divided into three groups: speakers of English as their first language, speakers of English as the second language and speakers of English as a foreign language. Explaining the difference between the categories of speakers of English as the second and foreign languages, he writes, "The main difference between a fluent speaker of English as a foreign language and the speaker of English as the second language depends on whether the English language is used in the country and in the speakers' family, and thus on whether English determines the language repertoire of one's personality" [4: 11].

However, the criterion for the presence in the country or region of the national variety of the English language for determining the English language speakers as speakers of English as the second language (L2) loses its force with the emergence of the global language. In the age of globalization, the countries which until recently were, according to Kachru's language model, outside the internal and external circles of using the English language, as a result of a tempestuous growth of international contacts and higher requirements for language skills in international English, found themselves in the external circle where the English language is used so widely that it can no longer be regarded as a foreign language. Japan, South Korea, Latin America and China, which were not included into the "Englishspeaking world area" before the acceleration of the globalization processes, no longer consider English as a foreign language alongside with other "international languages". A high demand for English language skills has brought about the emergence of the world community of teachers of English as the second language (ESL), which became possible as a result of the Information Revolution and formation of the World Wide Web (WWW), which provides an opportunity of responding to supply and demand in organizing the teaching and learning of English in any point of the globe on the basis of scores of websites advertising ESL teaching and providing the necessary support. The largest and the most perspective market for thousands of English language native speakers offering their services in ESL teaching is China. According to the database of the international organization, ESL Teachers Board, in China there are more than 550 English language schools, including schools for preschool children and professional schools, where English is used as a medium of instruction in teaching special disciplines. The teaching staff of English language schools in China is 
formed from native speakers of the English language from the main countries of the English speaking world - the USA, the United Kingdom, Canada, Australia and New Zealand [7: 1-11].

With the transformation of English into the global language, the native speakers form the main English-speaking countries, according to Graddol, lose their absolute control over the use and development of their language, which becomes a property of the whole world as the number of speakers of English as a second language is growing at an increasing rate. In the second research of 2006 into the prospects of English language development, Graddol described in the following way the peculiarities to teaching and learning English as a foreign language (EFL), which is becoming part of history: "Approaches to teaching EFL, the same as to teaching any foreign language, consider the learner as an outsider, as a foreigner - as a person trying to be accepted by the community of the target language. The target language is always someone's native language. A learner is regarded as a language tourist who is allowed to visit the country without the right of residence and who must respect the superior authority of the native speakers" [5: 82].

In connection with the English language acquiring the status of the global means of communication and with the transformation of English teaching into a multibillion dollar industry, the question of what the language of world communication is and in which ways it differs from national varieties of the English language becomes relevant. One of the characteristic features of the English language variability, which is not reduced to differences in grammatical and lexical structures of the two main varieties of the English language that have been formed historically as a result of the independent political development of the USA, leading to the emergence of the North American variety of the English language. The British variety, however, has retained its influence on all the other countries, the former English colonial possessions, and then - the countries of the Commonwealth (until 1947 - the British Commonwealth of Nations). Both main varieties of the English language - American English and British English, despite their obvious differences separating them from each other, are not homogeneous themselves. The British variety of the English language in Australia, New Zealand, South Africa and so on has its peculiarities, which allow considering the English languages in these countries as separate varieties. Variability of the American variety of the English language, in its turn, can be found not only in the certain differences between American and Canadian varieties, but in a considerable variability inside both the American and Canadian varieties of the English language. The English language variability is often considered by linguists, according to the American researcher James Milroy, as a "result of purely linguistic development independent from human activities in using the language in social and situational context". Milroy pointed out that variability is determined by social processes, and he drew attention to significant 
variability observed in synchronous studies of a language in language communities of our times, which are frequently underestimated in describing the standard forms of a language [7:2].

The notion of "English as the global language" presents a completely new phenomenon, even though many researchers of the English language use for international communication, yet long ago before the transformation of English into the global language, carried out notable research into English as a Lingua Franca (ELF) as a new research field, different from the study of the use of English as a national variety by the native speakers themselves. In early $21^{\text {st }}$ century, as Anna Mauranen writes in the preface to the collection of academic articles "English as a Lingua Franca" published in 2009, the study of the use of English as a Lingua Franca has become one of the "most vibrant research areas" [8: 2]. Mauranen describes the changes that have taken place in less than two decades since the start of research into the peculiarities of the use of English in international communication as follows, "The English language has undoubtedly established itself in the position of the global Lingua Franca. Besides this status, it has become a symbol of our times, alongside with globalization, social networks, economic integration and the Internet" [8: 1]. The global ELF researchers come forward against the continuing practice of using two leading varieties of the English language - American and British - in teaching and learning English as an international language. The researcher of the ELF phonetic peculiarities, Jennifer Jenkins, speaking at the first ELF conference in Helsinki in 2008, stated, "Taking into account the socio-linguistic fact that languages are formed by their users, and that nowadays the English language native speakers are in minority among the English language users, it will be more reasonable in teaching English to give up the almost exclusive concentration on the national varieties of the English language" [9: 11]. As an example of a lack of correspondence in promoting the use of national pronunciation norms to new sociolinguistic realities, Jenkins refers to continuing practice of support for British standard pronunciation RP (Received Pronunciation) in the systems of teaching English to foreigners. In spite of the fact that English as the language of worldwide communication is used mostly for interlingual and intercultural communication among the non-native speakers of English, educational materials for teaching and learning English, particularly in Europe, still present RP as an exemplary model of English pronunciation norms.

Basic arguments of the opponents of the use of national varieties in teaching pronunciation skills, including the new argument based on the thesis that native speakers have lost their right of ownership of the language as the number of speakers of English as the second language has exceeded considerably the aggregate population of the majority English speaking countries, are not supported not only by the teachers and directors of language schools, but by sociolinguists who insist on abiding by language standards. 
Thus, Peter Trudgill expressed his support for the national standard variants in the following way: "Even if the native speakers of English 'do not own' the English language, it is important that English comes from them, particularly historically, and abides in them" [10: 11-12].

The tendency of the emergence of multiple national English language varieties was noted by David Crystal in his works about the transformation of the English language into the global means of universal communication. A natural, in his opinion process of transformation of the Standard English variety into local language varieties expressing national identities will not lead to the fragmentation of the English language into mutually unintelligible English varieties, and will not interfere with the process of forming the English language as the language of worldwide communication. Fragmentation as, for example, in the case of the Latin language presents a common phenomenon, but, as Crystal writes in his paper "World English: Past, Present, Future", "The language history must not be a guide to us anymore" [11: 8]. He considers that as one of the consequences of globalization, the means of global communication allow people to provide unhindered excess to other languages and varieties of the English language. In his opinion, the satellite connection will lead to the creation of a "system of interconnection and inter-constraint", which will balance a tendency to the formation of national varieties differing from Standard English by striving to comprehensibility on a global scale, which, in its turn, will contribute to the convergence of national varieties and Standard English [11:8].

The process of transformation of the international English into the means of global communication at the turn of the $21^{\text {st }}$ century was proceeding so rapidly that the academic community failed to reach a consensus about the world's standard of English as the global language due to the insufficient research in the newly emerging field. The thesis concerning the necessity of recognizing the right of the language of worldwide communication to work out its own norms on the basis of studying the available research material contained in the database of the use of the international English by the speakers of English as the second language is not sufficiently convincing at the present stage of the world system of languages transformation, since it contradicts the theory and practice of emergence and development of languages. The number of speakers of a language, no doubt, is of importance for the value of the language as a cultural capital, but the control over the language development and the language standard forms is determined by political, economic and cultural influence of the main English speaking countries, even though the number of native speakers of English in these countries is lower than the number of the users of English as the second language in the world.

One must also note a certain limitation of the concept about a new, independent standard of English as the global language from the viewpoint of 
applying information theory to language communication. The basic ideas of information theory were initially expounded by Claude Shannon in his seminal paper "The Mathematical Theory of Communication" published in 1948 in the Bell System Technical Journal, and later in a book under the same title published in 1949 [12: 379-423]. Shannon proposed a model of a communication system of transmission and reception of signals from a transmitter to receiver, in which one of the most important elements is the communication channel used as a means of signal transmission. The transmission of a signal from a transmitter to receiver is often hindered due to the presence of noise in the communication channel in the form of break-ups in signal transmission and as a result of disturbances, resulting in errors in transmitting a message. Shannon demonstrated that using a system of signal coding and decoding can ensure correct information transmission in spite of noise in the communication channel [13: 280]. A communication process is one of the most typical processes of information transmission and receiving, to which the main ideas of information theory can be applied. There are four main elements in the process of information exchange: sender of the message, the message itself, information transmission channel and the receiver for whom the information is intended and who interprets it. An important problem of the communication process is the identification of the probable noise sources, understood as everything which distorts the meaning of the transmitted information, and search for the means of their removal.

In carrying out interlingual and intercultural communication, coding and decoding of information takes place on the basis of the English language, and in this process any deviations from the standard language forms connected with phonetical, grammatical and lexical phenomena lead to the emergence of noise in the information channel, and at certain levels of disturbance, they result in break-ups in communication. Typical mistakes in the speech of users of English as the second language, which proponents of the concept of the independence of the global language standard propose to fix as a norm, considerably increase noise in the information communication channel, and with the growth of quality and scales of language teaching may be brought to a minimum.

In connection with claims made by the leading linguists (for example, David Graddol) that the native speakers of English have lost their right of ownership of the language, and, therefore, their main standard varieties must not be regarded as the world standard of English, and also in connection with attempts to work out a new world standard of the global language on the basis of the 'characteristic features' of its use by non-native speakers of the language, whose number has exceeded the total population of the main English speaking countries, it is interesting to note that no reorientation has taken place in the activities of the multibillion dollar industry of English teaching and learning from reliance on the native speakers of English and from 
the use in language teaching of the two main language varieties - British English (BE) and American English (AE) to the non-native speakers of English and the "new world standard". The largest market for English language teaching in the world is found in China, where the annual turnover of the businesses dealing in ESL teaching at all levels makes up 10 billion yuan [14]. Every year, China hires 100 thousand 'foreign experts' from the main English speaking countries, and the basic requirement in getting a job of an English language teacher is proficiency in the main language standard. As Niu Qiang and Martin Wolff write in a paper about revolutionary transformations in English language teaching in China: "The only criterion in hiring English language teachers in China is the requirement of being a native speaker and having a bachelor degree, which must not necessarily be in the English language, literature, linguistics or education" [15].

China is no exception in carrying out the policies in selecting English language teachers for the network of public and private schools from English language native speakers - nationals of the main English speaking countries. A leading authority on questions concerning working abroad, Jean-Marc Hachey, the author of the bestseller "The Big Guide to Living and Working Overseas", in his article about carriers of English language teaching in foreign countries writes: "One billion people around the world want to learn English, so that finding an English language teaching job abroad is not hard ... Your job of an English language teacher is guaranteed if you are a native speaker, have a university degree and passed a short course of teaching English as a foreign language". Among the countries and regions with the highest demand for native speakers' educational services, Hachey singles out such 'hot markets' as Eastern Europe, Turkey, Korea, Taiwan, Hong Kong, China, Japan, as well as a number of countries in Latin America [16].

ESL teachers certification, which is traditionally organized by universities of Great Britain and the United States on the programs of TESOL (Teaching English to Speakers of Other Languages) and TEFL (Teaching English as a Foreign Language), has turned into a big business in organizing teaching courses and certification of the teachers of English as the second and foreign languages, including online mode teaching, in many countries of the world. As Tom Davidson remarks in an article about abuses in the industry of ESL and EFL teacher training and certification, due to the difficulties connected with the international certification system regulation, full-time courses and online courses are often taught by people passing as native speakers and having no educational credentials from any recognized accreditation bodies from the main English speaking countries. Before an international legislation in regulating the systems of training and certification of ESL and EFL teachers is passed, Davidson concludes, the main principle in this industry will be 'Caveat Emptor' (Latin for 'Let the buyer beware')[17]. 


\section{Discussion}

The question of Standard English is a source of heated arguments even in the case of national varieties of the English language. A wide spread of the English language in the post-World War II period and its acquiring the status of the global language at the turn of the $21^{\text {st }}$ century have made this question even more complicated. That the question about the standard of the global English language is far from solution can be seen in the fact that unlike other European languages the English language has not been codified, and the notion of 'standard' does not include prescriptive language forms, but is understood as a status-functional variety of the language associated with the educated elite. Peter Trudgill defines Standard English as "a variety of the English language that is used in written and oral forms in the English speaking countries of the whole world, and, therefore, the variety spoken by 'educated people', and which is used in teaching English to all those for whom the English language is not native" [18: 117-128]. In the absence of a generally accepted world standard of the English language, Peter Trudgill and Jean Hannah in their book "International English" refer to the wide spread practice in teaching English (in countries where English is not a state language) which is based on the choice of one of the most influential national varieties - British Standard of the English language, which they call 'English English (EngEng)' or American Standard of the English language, which they call 'North American English (NAmEng)'. The British variety, as Trudgill and Hannah write, means "standard English in its written and oral forms used by educated speakers in England and, with a few differences, in Wales, Scotland, Northern Ireland, Irish Republic, Australia, New Zealand and South Africa". The American variety is understood by them as "English used in its oral and written forms by the educated speakers in the USA and Canada" [10: 1-2].

The absence in English speaking countries of special state organs, like Académie française in France, with the purpose of studying the national language and literature and forming the language and literary norms of the national language, is puzzling in those countries where the codification of the national language norms is part of the national legislature. Even a greater uncertainty in relation to what the 'proper English language' is and which language forms are not 'standard', takes place in teaching English as the second language (L2) or foreign language (EFL). In a paper presented in March, 2000 at a working seminar in Paris on prescriptivism in teaching foreign languages, the British linguist Richard Hudson expressed his opinion that a codification of the English language would be useful for the English people themselves in school teaching. Hudson pointed out that a high demand for textbooks of English as a foreign language has brought about a high degree of codification of the English language for foreigners. On the 
other hand, it is the descriptive form of teaching grammar that is practiced in Great Britain's schools. The National Curriculum of 1999 contains no warnings about undesirability of using non-standard forms. The school students are not informed about the list of non-standard forms that must be avoided in oral and written speech. Hudson takes exception to the widely spread opinion that native speakers of English do not need a description of their own language. Referring to Peter Trudgill's estimate, confirmed by his own research that Standard English is native only to 10 percent of the population, Hudson rejects the argument that teaching Standard English in the UK's schools is unnecessary. "Recent changes in our system of education, - writes Hudson further, - have shown a necessity of teaching Standard English to some 90 percent of people who are not proficient in the normative language, rather than remonstrating with them to use it ... The time has come for another fundamental shift in British culture, this time in the direction to a distinct and clear codification of Standard English for the native speakers themselves" [19].

A formal standardization of the English language is also absent in the USA, where language norms are prescribed in grammar and language usage textbooks, but not by the National Language Regulators. However, the absence of formal standardization does not interfere with the maintenance of Standard English on the basis of the system of national education responsible for English language teaching. As Walt Wolfram and Natalie Schilling-Estes write in their book about variability in American English, "Without an official agency responsible for the maintenance of uniform formal Standard English, one can expect differences of opinion between prescriptive grammarians, but there is a high degree of agreement in most cases" [20: 10].

A critical attitude to deviations from standard varieties of the English language in the process of formation of new English language varieties in countries where it traditionally fulfilled the function of the means of interlingual communication can be found in the use of the contemptuous expression 'broken English' in relation to numerous forms of English that have emerged in in former colonies of the British empire and in countries taking an active part in world trade. A change of attitude in relation to 'non-standard forms' was the result of recognition of the English language transformation into the universal language of worldwide communication, which demanded refusal from the notion of 'English as a foreign language' and the use of an ideal native speaker model in English language teaching. As the British linguist Randolph Quirk pointed out yet in early 1960s, the ideas about the English language as the Englishman's gift and that English remains fundamentally the language of its native speakers are narrow-minded and naïve, do not correspond to realities and can only harm the cause of improving human relations and establishing international harmony [21].

In 1994, Patrick Blanche in his article "Is the International Language 'Broken English'?' analyzed the reasons of the success of the wide spread- 
ing of English and emergence of its multiple forms, and came to conclusion that "in connection with the growth of demand around the world for intercultural communication, it must be recognized that the phrase 'broken English' has outlived itself" [22: 6]. As a proof of his thesis about a gradual transformation of the English language into the universal language of global communication he adduced evidence about an ever greater number of non-native speakers of English accepting it 'from inside' as their language, and that the volume of fiction literature in English produced by authors from many countries of the world, particularly on the Indian subcontinent, Eastern and Southern Africa and on the islands of the Caribbean, is growing continuously [22: 7]. Blanche emphasized the importance of maintaining local languages and cultures in order that English perform its role of the language of worldwide communication more effectively, "Peoples strive for harmony without losing their identities, and they ... want establishing better relations without losing their values and cultural heritage" [22: 11]. Summarizing, Blanche expressed his opinion that "it would be useful to consider that the international English language has no native speakers, and is a tool which anyone can learn to use skillfully with due account of the language situation in order to improve communication in the whole world" [22: 12].

It should be, however, noted that both Quirk and Blanche while criticizing the unjustified arrogance of the Standard English variety defenders vis-à-vis numerous national forms in countries where the English language has become widely accepted as a means of interlingual and intercultural communication, came out in defense of national and regional modifications of the standard British variety, which manifest themselves in colloquial speech and lexis, reflecting the local cultural identities and saturated with cultural realities. Indian English and Pakistani English in Asia, Nigerian English, Ghanaian English in Africa and others, with all their insignificant deviations from the standard variety, are the forms of the standard British variety that have emerged in the local conditions. In all spheres of formal communication in countries where English is the official or one of the official languages, it is the standard variety of the English language that is used, with differences from the standard form manifesting themselves only in pronunciation. In the spheres of unofficial English language use, Pidgins and Creoles formed on the basis of English and serving as means of interlingual communication among the people who do not speak Standard English varieties reserved for education and state government, are in wide circulation. The existence of numerous varieties of English throughout the world, however, does not interfere with the use of its standard, internationally accepted form, which has acquired the global lingua franca status due to its superior communicative value, as an important tool of international communication [23: 67-68].

After acquiring independence, countries that accepted English as official or state language, as a rule, directed their efforts on depidginizing and 
decreolizing their populations, declaring all nonstandard forms to be 'broken English' resulting from an insufficiently developed systems of national education. Therefore, a struggle against non-standard varieties of the English language very often takes the form of campaigns for promoting literacy and adult education. Only in some countries, like, for example, in the most multilingual country of the world, Papua-New Guiney, nativization (transforming pidgins into Creole languages) received a state support. Thus, NewGuinean's pidgin, Tok Pisin, turned into the native language of a part of the population and into a convenient means of general communication in a country where only a small minority of the population are proficient in Standard English [24: 3].

\section{Conclusion}

The transformation of English into the language of global communication demands a revision of the traditional approach to teaching foreign languages. English as the language of worldwide communication loses its status of a foreign language. It calls for a reorganization of language education that envisages a transition to multilingual teaching based on teaching English not as one of the two major national varieties of the English languages, which leads to acquisition of corresponding dominant cultures, but as the language of worldwide communication used for overcoming interlingual and intercultural barriers in the globalized world. The transition to multilingual teaching is based on regarding the English language as a necessary condition of a knowledge society individual's entry into the world's economic, political and cultural areas, and includes, apart from one's native (or state language) and the English language, teaching and learning of one of the foreign languages offered by the national system of education.

\section{References}

1. Schutz, R.: English - The International Language // English Made in Brazil. URL: http: // www. sk.com.br/sk.ingl.htm/. Retrieved: 06.09.2017.

2. Education \& Training 2010: Work program adopted by the European Commission in 2001 (2005). // ETUCE Circular 2/2005

3. A New Framework Strategy for Multilingualism. // COM (2005) 596 final (Brussels). (2005)

4. Graddol, D.: The Future of English? A guide to forecasting the popularity of the English language in the $21^{\text {st }}$ century. London: The British Council. (2000).

5. Graddol, D.: English Next: Why Global English May Mean the End of English as a Foreign Language. London: The British Council. (2006)

6. Kachru, B.: Standards codification and sociolinguistic realism: The English language in the outer circle // R. Quirk and H. Widdowson (eds.). English in the world: Teaching and learning the language and literatures. Cambridge: Cambridge University Press. (1985)

7. Milroy, J.: Variability, Language Change, and the History of English // Institutional Journal of English Studies (University of Murcia). Vol. 5. 1. (2005) 
8. Mauranen, A., Raita, E.: English as a Lingua Franca: Studies and Findings. Cambridge Scholars Publishing. (2009)

9. Jenkins, J.: ELF Speakers' Perceptions of Their Accents // Mauranen, A. \& Elina Raita (eds.). English as a Lingua Franca. Cambridge Scholars Publishing. (2009)

10. Trudgill, P., Hannah, J.: International English: A Guide to the Varieties of Standard English. $4^{\text {th }}$ ed. London: Arnold. (2002)

11. Crystal, D.: World English: Past, Present, Future // Proceedings of the ASKO EuropaStiftung Symposium, 11-13 June 1999. URL: http://www.davidcrystal.com/ DC_articles/English28.pdf. Retrieved: 10.09.17. (1999)

12. Shannon, C., Weaver, W.: The Mathematical Theory of Communication // Bell System Technical Journal. 27. pp. 379-423. (1949)

13. McEliece, R.J.: Information Theory // Encarta Encyclopedia Deluxe. (2001)

14. English Language Training Profitable Industry in China // People's Daily, 1/23/02.

15. Qiang, N., Wolff, M.: EFL/ESL Teaching in China: Questions - Questions - Questions // M. Wolff (ed.). Teaching EFL in China: What Every Foreign Teacher Should Know Before They Go. New York: Nova Science Publishers. (2004)

16. Bastardas-Boada, A.: Linguistic Sustainability for a Multilingual Humanity // Linguistic Diversity, Sustainability and Peace: Proceedings of the X Linguapax Congress, Forum. Barcelona: University of Barcelona. pp.1.

17. Hachey, J.M.: Teach English Overseas. A Stepping Stone to International Careers // Transitions Abroad Magazine. January/February Issue. (2006)

18. Davidson, T.: TESOL Certificates. Teaching or Deceiving the EFL/ESL Teaching Profession // TESOL Law Journal. Vol. 2. (2008)

19. Trudgill, P.: Standard English: What it isn't // Bex T.; Watts R.J. (eds.). Standard English: the Widening Debate. London: Routledge. (1999)

20. Hudson, R.: The language teacher and descriptive versus prescriptive norms: The educational context // Workshop on prescriptivism and foreign language teaching. Paris. (2000)

21. Wolfram, W.; Schilling-Estes N.: American English: dialects and variation. $2^{\text {nd }}$ Ed. Malden, MA: Blackwell. (2006)

22. Quirk, R.: The Use of English. London: Longman. (1960)

23. Blanche, P.: Is the International Language "Broken English"? // Research Reports of Kochi University. Humanities. 43. pp. 1-14. (1994)

24. Smokotin, V.M., Petrova, G.I., Gural, S.K.: The role of natural languages as lingua francas in the course of human history // Jazyk i Kultura - Language and Culture. 9. pp. 6768. (2017). (In Russian)

25. Constitution of the Independent State of Papua New Guiney. Port Moresby: PNG National Legislation. (2000)

Information about the authors:

Smokotin Vladimir M. - D.Sc. (Philosophy and Culture), Professor, Faculty of Foreign Languages, Tomsk State University, Tomsk, Russia, vladimirsmokotin@yandex.ru

Petrova Galina I. - D.Sc. (Philosophy), Professor, Faculty of Philosophy, Tomsk State University, Tomsk, Russia, seminar2008@mail.ru

Gural Svetlana K. - Ds.Sc. (Education), Professor, Faculty of Foreign Languages, Tomsk State University, Tomsk, Russia, gural.svetlana@mail.ru 